\title{
Utilização de Bloquinhos de Montagem LEGO® para o Ensino dos Conceitos do Sistema Toyota de Produção
}

\author{
Alexandre Ferreira de Pinho (UNIFEI) pinho@unifei.edu.br \\ Fabiano Leal (UNIFEI) fleal@unifei.edu.br \\ Dagoberto Alves de Almeida (UNIFEI) dagoberto@unifei.edu.br
}

\begin{abstract}
Resumo
Este artigo mostra como é possível facilitar o aprendizado dos conceitos sobre o Sistema Toyota de Produção. É utilizada uma dinâmica de ensino através de bloquinhos de montagem LEGO ${ }^{\circledR}$ batizada de MIB - Montagem Interativa de Bloquinhos. Esta dinâmica além de abordar os principais conceitos sobre o Sistema de Toyota de Produção, também utiliza os conceitos sobre Just-in-time (JIT), tempo de setup, metodologia $5 S$ e nivelamento de produção (Heijunka). O artigo descreve as quatro rodadas utilizadas na dinâmica MIB e como os conceitos descritos anteriormente são transmitidos aos alunos.
\end{abstract}

Palavras-Chave: Sistema Toyota de Produção, Ensino de Engenharia de Produção.

\section{Introdução}

A utilização dos bloquinhos de montagem da LEGO® é chamada, pelos professores que a utilizam, de Dinâmica MIB (Montagem Interativa de Bloquinhos). Esta dinâmica vem sendo aplicada na Universidade Federal de Itajubá desde Junho de 2003, associada ao tema "Sistema Toyota de Produção", e é utilizada na graduação e na pós-graduação em Engenharia de Produção desta instituição. A Dinâmica MIB representa um sistema de produção que é inicialmente caracterizado por ser do tipo "empurrado" (quando um trabalho é finalizado num posto, o resultado da operação é "empurrado" para a próxima estação ou para o inventário final), e que, ao final, torna-se um sistema do tipo "puxado" (cada estação "puxa" o resultado da montagem da estação anterior, de acordo com o necessário, e os produtos finais da operação são "puxados" pelo cliente de acordo com sua demanda).

Esta dinâmica se caracteriza por ser um modelo de aprendizagem vivencial, pois segundo Kolb (1997) esta dinâmica enfatiza a experiência no processo de aprendizagem. Para que ocorra o aprendizado é necessário, que as pessoas se envolvam completa e abertamente em novas experiências concretas. Em seguida, é necessário refletir sobre essas experiências e observá-las a partir de outras perspectivas. Depois, as conclusões obtidas devem ser generalizadas, criando-se novos conceitos que consigam integrar as observações em teorias lógicas. No final, deve-se transferir, ou mesmo testar, estes conceitos em novas situações, modificando procedimentos, tomando decisões ou resolvendo problemas.

O objetivo deste trabalho é descrever a Dinâmica MIB utilizada em sala de aula e demonstrar como os recursos visuais que esta dinâmica proporciona facilita o aprendizado dos alunos de graduação e pós-graduação. Nesta dinâmica, as equipes podem tomar diferentes decisões durante suas quatro rodadas e acompanhar os resultados de suas decisões. Também serão abordados, neste artigo, os conceitos envolvidos para a realização desta dinâmica. 


\section{Sistema Toyota de Produção}

A partir dos anos 80 o desenvolvimento industrial japonês deu-se principalmente nos aspectos de gerenciamento da qualidade, emprego da automação e técnicas de marketing reverso, ou seja, partindo-se do foco do cliente, chega-se à organização, passando pelo desenvolvimento de novos produtos, novas aplicações para os produtos existentes, novas embalagens, etc., invertendo a rota usual de negócios e estabelecendo o que Coriat (1994) chamou de "Pensar pelo avesso". Entre outras razões, reside um modo de gerir o negócio, subsidiado por uma mudança de paradigma: o Sistema Toyota de Produção e um de seus pilares, o paradigma Just-in-Time.

O Sistema Toyota de Produção foi forjado ao longo de vinte anos, incorporando conceitos oriundos da genialidade de seus criadores. Citam-se:

- A abordagem sistemática dos cinco porquês para a causa fundamental dos problemas;

- A autonomação (Jidoka), que dá autonomia à máquina para parar a linha em caso de produção defeituosa, ligada à separação entre homem e máquina, obtida pela multifuncionalidade de operadores e operação via layout celular;

- O Just-in-Time, apoiado no kanban, que reduz os estoques intermediários, fornecendo os materiais no local, na hora, na qualidade e na quantidade necessária;

- As sete perdas descritas por Shingo (1996), com base no princípio da completa eliminação de perdas, de Ohno (1997), originado no desafio lançado por Kiichiro Toyoda, de alcançar a competitividade industrial da América em três anos.

\subsection{As Perdas no Sistema Toyota de Produção}

O Sistema Toyota de Produção persegue a completa eliminação das perdas, vinculada ao objetivo da redução de custo, fundamental à sobrevivência da organização. Busca também maximizar o trabalho que agrega valor, ou seja, aquele que transforma o material ou faz uma montagem, e reduzir progressivamente o trabalho que não agrega valor, abolindo toda forma de perda. Para que se focalize o combate aos desperdícios na organização, o Sistema Toyota de Produção classifica sete tipos de perdas: 1) perda por superprodução; 2) perda por transporte; 3) perda por processamento; 4) perda por produção de não-qualidade; 5) perda por movimentações ergonômicas; 6) perda por espera; 7) perda por estoque.

A superprodução se dá por produção excessiva e por produção antes da hora, sendo a perda mais perseguida na Toyota. Ohno (1997) considera que a perda por superprodução é a pior das perdas, pois esconde e evita que sejam combatidas as ineficiências por toda a empresa, surgindo os efeitos danosos originados do excesso de estoques. Este enfoque trouxe um substancial aumento no padrão de vida do Japão e a perda da posição hegemônica de muitas indústrias ocidentais. Para Coriat (1994), o Sistema Toyota de Produção não é uma técnica de produção com estoque zero. Este é apenas um dos resultados a que ele conduz, perseguindo um objetivo muito mais geral, que é a prevenção das perdas. Ohno (1997) parte da redução do estoque para descobrir os desperdícios e racionalizar a produção.

\subsection{Just-in-time (JIT)}

Segundo a visão do criador da filosofia JIT, Ohno (1997), Just-in-Time significa que em um processo produtivo onde estejam envolvidos clientes e fornecedores, os componentes devem chegar à linha de montagem corretamente no momento e quantidades certas.

Para Shingo (1996), sistema JIT de produção é 80\% eliminação das perdas, 15\% um sistema de produção e apenas $5 \%$ kanban, esta exposição é pertinente, pois não são poucos os que 
confundem kanban com o JIT. Kanban é simplesmente um meio, ou uma das ferramentas, para se chegar ao JIT.

De acordo com Tubino (2000) o JIT seria uma filosofia voltada para a otimização da produção e o TQC (Controle Total da Qualidade) seria uma filosofia voltada para identificação, análise e solução de problemas, sendo que para uma melhor compreensão das ferramentas que os compõem é conveniente mantê-los em conjunto.

Slack (1999) relaciona as técnicas específicas que o sistema de produção JIT utiliza para o planejamento e controle como:

- A programação puxada, que coloca no cliente a responsabilidade de solicitar a entrega de materiais, em vez do fornecedor ter que enviar mais materiais;

- O sistema de controle kanban, o qual é muitas vezes visto equivocadamente como um equivalente ao JIT;

- A programação nivelada, que procura suavizar o fluxo de produtos da produção através da redução do período em que uma determinada seqüência de produção é repetida;

- A sincronização, que é o processo pelo qual o ritmo da produção é regularizado para produtos de alto volume.

\subsection{Tempo de Setup}

O Tempo de Setup é definido como o tempo decorrido da troca de processo da produção da última peça boa de um lote até a produção da primeira peça boa do outro lote. Como o Sistema Toyota de Produção baseia-se na eliminação do desperdício, a redução do Tempo de Setup é muito importante, pois visa eliminar o tempo desnecessário para se efetuar a troca de ferramentas de um equipamento. Os tempos de setup podem ser reduzidos através de uma série de métodos que são conhecidos como sistema de Troca Rápida de Ferramentas (TRF). Atualmente, fala-se em termos de SMED (Single Minute for Exchange or Die) e OTED (One Touch Exchange or Die). De acordo com Shingo (1996), a adoção da troca rápida de ferramentas (TRF) é a maneira mais eficaz de reduzir Tempo de Setup.

Algumas mudanças mecânicas nos equipamentos também auxiliam a baixar o Tempo de Setup, como, por exemplo, a padronização dos dispositivos de fixação, utilizando um único tamanho de parafusos.

Outra abordagem comum para a redução do Tempo de Setup é converter o trabalho que era anteriormente executado quando a máquina estava parada (denominado como setup interno), para ser executado enquanto a máquina está operando (denominado setup externo).

\subsection{Metodologia 5S}

Esta é uma metodologia de trabalho e de mudanças comportamentais, fundamentada no comprometimento das pessoas, que, combinando suas ações profissionais e pessoais, criam um ambiente mais organizado para uma melhor qualidade de vida.

A metodologia tem como principais objetivos mudar comportamentos e aprimorar atitudes, trocar informações entre funcionários e/ou áreas, contribuindo para uma administração mais participativa e de maior responsabilidade de todos com as condições de trabalho da empresa. Os 5 S's são baseados em cinco palavras japonesas: Seiri (Senso de Utilização), Seiton (Senso de Organização), Seiso (Senso de Limpeza), Seiketsu (Senso de Conservação) e Shitsuke (Senso de Autodisciplina).

- Senso de Utilização: separar e manter no local de trabalho somente os materiais, máquinas e equipamentos necessários, descartando ou eliminando os desnecessários. 
- Senso de Organização: definir a forma correta e o local adequado para a guarda de materiais, máquinas e equipamentos, tornando seu acesso rápido e fácil.

- Senso de Limpeza: eliminar a sujeira de materiais, máquinas e equipamentos do local de trabalho, atacando as fontes do problema.

- Senso de Conservação: garantir a continuidade das condições físicas e da saúde no local de trabalho.

- Senso de Autodisciplina: cumprir os procedimentos e as normas mantendo o hábito naturalmente.

\subsection{Nivelamento de Produção (Heijunka)}

É uma programação de produção nivelada através da ordenação dos pedidos para corresponder à demanda. Com o nivelamento da produção evita-se produzir grandes lotes, podendo-se combinar diferentes produtos para garantir o fluxo contínuo, minimizar inventários e estabilizar a produção. De acordo com Shingo (1996), há três maneiras de nivelar quantidades: 1) padronizar processos numa linha de produção, a partir da capacidade de processamento mais alta; 2) padronizar processos numa linha de produção, a partir da capacidade de processamento mais baixa; 3) equilibrar quantidades de produção no nível necessário para que satisfaçam as exigências determinadas pelos pedidos.

A terceira alternativa é a que melhor identifica a filosofia JIT, pois permite realizar o nivelamento da produção em lotes, baseado nas necessidades do mercado consumidor.

Conforme Shingo (1996) e Hay (1988), o mais importante benefício de se produzir lotes menores é que o lote pequeno estabelece as bases para um nivelamento entre a produção e a demanda. Há ainda outros benefícios que uma empresa pode esperar, tais como o aperfeiçoamento através da curva de aprendizagem, aumento da flexibilidade do mix de produtos, redução de estoques, menor tempo de supervisão e melhoria da qualidade.

Com a produção nivelada, a única informação necessária para programação da produção é o programa de montagem final, que pode ser flexibilizado de acordo com a demanda atual do mercado. O chão-de-fábrica trabalharia com o sistema de produção puxada baseada na demanda do produto final.

Segundo Hay (1988), entre os componentes para eliminação do desperdício, ou seja, atividades que não agregam valor, um dos mais importantes para o JIT é o conceito de nivelamento, sincronização e fluxo. A filosofia do JIT estabelece que o nivelamento é necessário para o fluxo, e que é de vital importância, mais até que a velocidade.

\section{Dinâmica de Ensino}

Atualmente muitos cursos no mundo inteiro têm utilizado a aplicação de jogos de empresas como forma complementar de ensino.

O jogo de empresas é o tipo de dinâmica na qual se realiza um exercício de tomada de decisão em seqüência, buscando o treinamento sistemático de uma equipe ou conjunto de equipes, trabalhando sobre o modelo de uma operação empresarial no qual os participantes assumem posições definidas como se estivessem dentro de uma empresa MURY (2002). Sua principal utilização nos dias de hoje se dá principalmente no treinamento empresarial. No entanto, uma das dificuldades encontradas é fazer com que o modelo se aproxime o máximo possível da realidade. É uma excelente ferramenta de ensino, baseando-se geralmente em modelos matemáticos que buscam simular o comportamento econômico, empresarial e organizacional.

Porém, no Brasil, essa prática ainda é pouco apreciada, pois, para algumas pessoas, os jogos empresariais ainda possuem conotação puramente lúdica e de perda de tempo MIYASHITA 
(2003). A validade de tais jogos é ainda um paradigma em fase de mudança. As experiências de educadores de diversas instituições no mundo inteiro têm sido positivas e promovem uma transformação na forma de se encarar a complementaridade dos jogos, quando aliados aos métodos tradicionais de ensino. Nas universidades, os jogos conseguem auxiliar no desenvolvimento de diversos aspectos: visão sistêmica, tratamento do viés cognitivo, trabalho em equipe, liderança, dinâmica de sistemas, relacionamento das áreas das empresas, espírito crítico nas decisões etc. Para que a mudança de paradigma ocorra, são necessários a elaboração de jogos com propósitos específicos para a aplicação nas diversas áreas da Engenharia de Produção. Além disso, deve haver também a conscientização dos educadores, seja pela experiência de terceiros, bem como pelos estudos, qualitativos e quantitativos, feitos sobre jogos de empresas, da necessidade de agregar valor a seus cursos, tornando-os mais produtivos e eficazes.

\subsection{A Dinâmica com Bloquinhos de Montagem LEGO ${ }^{\circledR}$}

A dinâmica aqui proposta é baseada em uma dinâmica utilizada pelo grupo ALCOA, porém adaptada ao cenário acadêmico, a fim de ilustrar algumas técnicas e conceitos envolvidos no Sistema Toyota de Produção. Cabe ressaltar que além das fotos que serão mostradas neste artigo, é realizada, também, uma filmagem da dinâmica. Este filmagem é utilizada como instrumento adicional para a motivação dos estudantes, uma vez que esta filmagem é entregue aos alunos para que este possa se auto-avaliar.

A dinâmica consiste na montagem de bloquinhos $L E G O \AA$, que representam linhas de montagem em uma fábrica. A fábrica produzirá três tipos de produtos finais, conforme mostra a figura 1 .

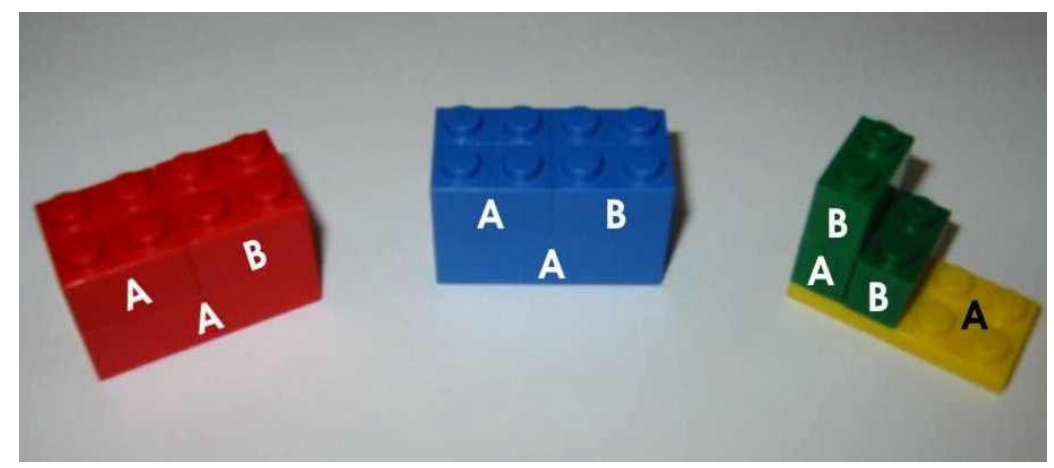

Figura 1 - Peças a serem montadas, com as letras indicando a responsabilidade de cada Operador.

Cada grupo participante é dividido em no mínimo três componentes:

- Operador A: responsável pela primeira parte da montagem (ver figura 1);

- Operador B: responsável pela segunda parte da montagem (ver figura 1). Este deve preparar o setup da máquina antes de efetuar a montagem, o qual foi propositalmente definido para tomar tempo deste operador;

- Expedição: responsável pelo embarque no caminhão. $\mathrm{O}$ embarque deve seguir a ordem imposta pelo cliente (cores nos caminhões).

Entrega-se então para cada grupo a seqüência de montagem de cada um deles e a folha com os caminhões para embarque à Expedição.

É estipulado um tempo total de 4 minutos por rodada para o embarque de 30 peças. Assim, o ritmo de produção (takt time) de cada peça é de 8 segundos. As equipes são informadas deste tempo. 
A dinâmica consiste de quatro rodadas, descritas a seguir:

\section{Rodada 1:}

As peças são colocadas sobre a mesa de cada grupo de maneira desorganizada (figura 2). $\mathrm{O}$ Operador $A$ segue sua seqüência de montagem o mais rápido possível. O Operador $B$, por sua vez, segue sua seqüência, porém aguardando as peças semi-acabadas provenientes do Operador $A$. Não é permitido adiantar a produção, desrespeitando a seqüência préestabelecida. As seqüências são impostas e diferentes.

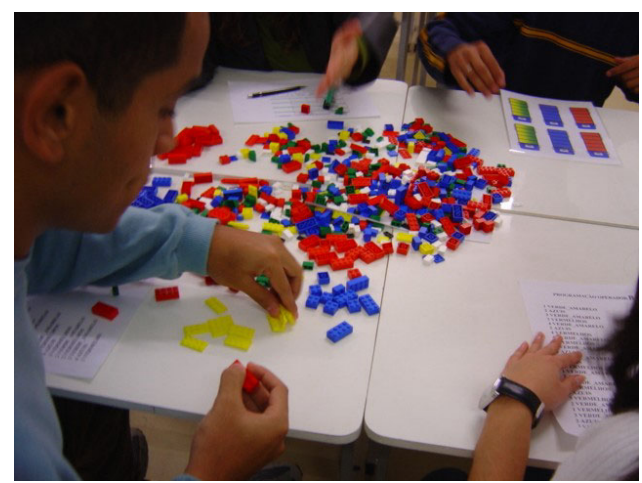

Figura 2 - Peças sem organização.

As peças acabadas são entregues a Expedição, que deve carregar os caminhões na seqüência de cores estabelecida.

Ao final da rodada preenche-se a planilha de dados. É importante ressaltar que para o "Custo das peças não-acabadas", estas devem ser contadas em dobro, pois cada produto não-acabado possui dois bloquinhos. Para o "Custo das peças acabadas", cada peça pronta será equivalente a uma unidade.

Um componente de cada grupo deve expor seus resultados: o percentual de entrega além do lucro ou prejuízo final.

É comum observar nesta rodada que as equipes não atingem a meta de produção, obtendo prejuízo devido ao custo do estoque gerado entre processos.

Ao final da primeira rodada abre-se, então, uma discussão sobre melhorias que podem ser implementadas na linha de produção. Desta forma, é introduzido o conceito dos 5 S's.

\section{Rodada 2:}

De acordo com o conceito dos $5 \mathrm{~S}$ 's, organizam-se e separam-se as peças (figura 3). As nãoúteis são guardadas. Repeti-se então o mesmo esquema da rodada 1.

Ao final desta rodada, abre-se novamente a discussão, introduzindo o conceito de kanban.

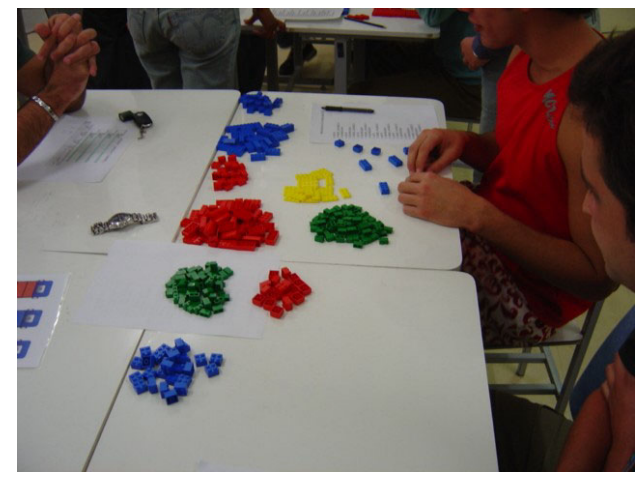

Figura 3 - Peças organizadas após 5 S’s. 


\section{Rodada 3:}

Cada grupo participante decide qual seqüência de montagem será substituída pelo kanban (figura 4). Retira-se então, a seqüência escolhida, substituindo-a por um cartão kanban. Este cartão é previamente preenchido com as respectivas montagens, sendo uma peça em cada espaço. Repete-se o esquema da rodada anterior, porém com somente uma seqüência de montagem, sendo a outra "puxada" pelo posto de trabalho posterior à mesma.

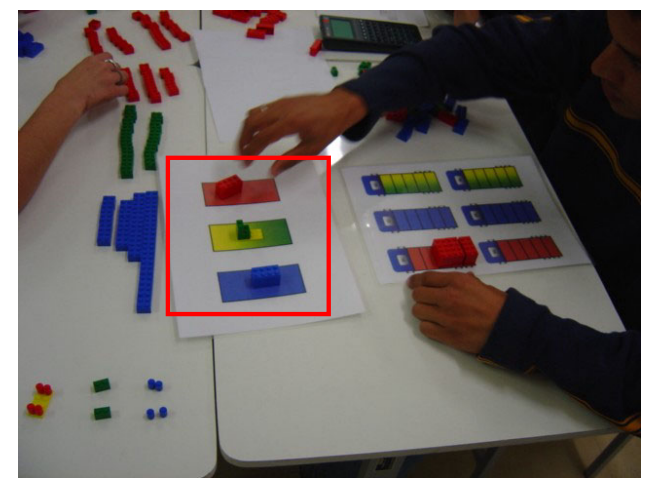

Figura 4 - Substituição de 1 seqüência por kanban (em destaque).

Ao final da rodada, discute-se se foi válida ou não a substituição da seqüência de montagem por um cartão kanban. Salienta-se que a substituição mais adequada seria a da seqüência do Operador $B$, uma vez que o mesmo está mais próximo ao cliente.

Introduz-se aqui o conceito de TRF, substituindo então o setup tradicional por um do tipo OTED (figura 5), aonde o Operador B passou a não mais necessitar montá-lo, e sim apenas pressionar um botão, reduzindo o tempo de setup. Introduz-se ainda o conceito de nivelamento.

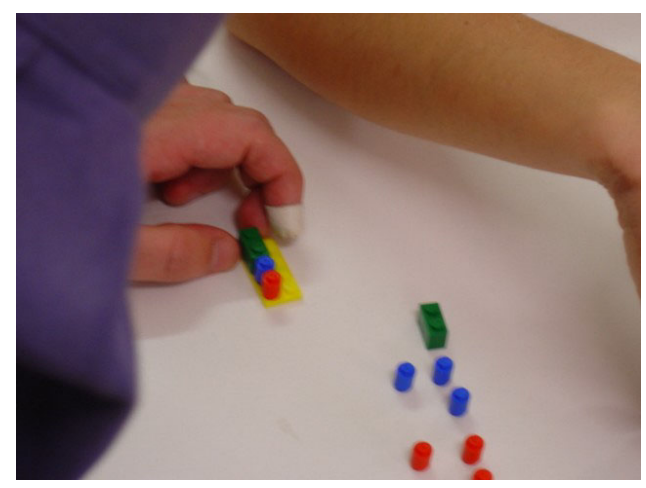

Figura 5 - Detalhe do OTED

\section{Rodada 4:}

Substitui-se agora também a seqüência do operador restante por outro cartão kanban. Além disto, é substituída a folha com o desenho dos caminhões que só carregam um tipo de peça por vez por uma com caminhões que podem carregar peças misturadas, representando o nivelamento de produção (figura 6).

Os cartões kanban foram previamente preenchidos com suas respectivas montagens, sendo uma peça em cada espaço. A partir deste ponto, é a Expedição que "puxou" a produção.

Após esta rodada, observa-se que as equipes cumpriram a meta com um custo mínimo de estoque (somente o material do kanban). 


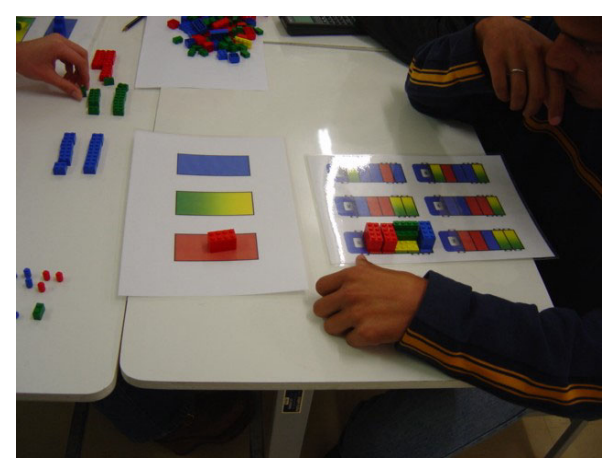

Figura 6-Kanban + Nivelamento.

Ao final desta rodada, cada equipe retira as três primeiras peças embarcadas no primeiro caminhão. Introduz-se o conceito de takt time, ou ritmo de produção. A cada 8 segundos uma peça deveria ser produzida e embarcada, ou seja, os operadores só deveriam produzir ao comando do palestrante. Esta ação visou mostrar às equipes que a organização da linha de produção possibilitou atender o takt time com tranqüilidade, algo inconcebível na rodada 1.

\section{Conclusão}

A aplicação da dinâmica $M I B$ com os alunos da graduação e pós-graduação das turmas de Engenharia de Produção mostrou-se bastante interessante. Esta dinâmica passou a ser um recurso visual adicional para o ensino de Engenharia de Produção.

Os conceitos sobre o Sistema Toyota de Produção, Just-in-time (JIT), tempo de setup, metodologia 5S e nivelamento de produção (Heijunka) são facilmente transmitidos para os alunos, além de tornar a aula bem mais atraente do ponto de vista didático.

Como futuro desenvolvimento pensa-se em realizar uma simulação discreta das rodadas desta dinâmica utilizando-se de softwares específicos. A intenção é obter uma validação estatística e mais suporte pedagógico.

\section{Referências}

CORIAT, Benjamin (1994)- Pensar pelo avesso, Ed. Revan, Rio de Janeiro.

HAY, Edward J. (1988) - The Just-in-Time Breakthrough: Implementing the New Manufacturing Basics, John Wiley and Sons, Inc, USA.

KOLB, D. A. (1997) - A gestão e o processo de aprendizagem. In: STARKEY, K. Como as organizações aprendem: relatos do sucesso das grandes empresas. São Paulo: Futura, p.321.

ISHIKAWA, Kaoru (1993) - Controle de qualidade total, Ed. Campus, Rio de Janeiro.

MIYASHITA, Ricardo (2003) - Os jogos de empresas como instrumento de treinamento em logística empresarial, Artigo, UFRJ, Rio de Janeiro.

MURY, A. R. (2002) - Simulando a cadeia de suprimento através de um jogo logístico: um processo de treinamento, Tese de Doutorado, COPPE/UFRJ, Rio de Janeiro.

OHNO, Taiichi (1997) - O Sistema Toyota de Produção: além da produção em larga escala, Bookman, Porto Alegre.

SHINGO, Shigeo (1996) - O Sistema Toyota de Produção do Ponto de Vista da Engenharia de Produção, Artes Médicas, Porto Alegre.

SLACK, Nigel; CHAMBERS, Stuart; HARLAND, Christine; HARRISON, Alan \& JOHNSTON, Robert (1996). Administração da produção. Editora Atlas S.A.

TUBINO, Dalvio F. (2000) - Manual de Planejamento e Controle da Produção, Atlas, São Paulo. 